\title{
The influence of hydrostatic pressure on the interlaminar fracture toughness of carbon/epoxy composites TITRE
}

\author{
D. Cartié ${ }^{a, *}$, P. Davies ${ }^{b}$, M. Peleau ${ }^{b}$ and I.K. Partridge ${ }^{a}$ \\ ${ }^{a}$ Department of Advanced Materials, Cranfield University, Bedford MK43 OAL, England, UK \\ ${ }^{\mathrm{b}}$ Materials and Structures Group, IFREMER Brest Centre, F29280 Plouzané, France \\ *: Corresponding author: Tel.: +44 1234750 111; fax: +44 1234 752460; email : d.d.r.cartie@cranfield.ac.uk
}

\begin{abstract}
:
The use of composites for deep sea applications requires a thorough understanding of the behaviour of these materials. While several studies have examined the influence of pressure on in-plane properties few data are available for the interlaminar fracture behaviour. This paper presents results from such tests performed in a specially designed pressure vessel mounted on a standard test machine, which allows pressures up to 1000 bars $(100 \mathrm{MPa})$ to be applied during mechanical testing. Mode I and Mode II tests have been performed on a unidirectional IM7/977-2 carbon/epoxy composite. No effect of pressure was noted on Mode I fracture toughness. A data reduction scheme has been developed for Mode II loading and an increase in $G_{\| C}$ with increasing pressure was noted.
\end{abstract}

Keywords: B. Fracture toughness; Mechanical properties; Fracture 


\section{INTRODUCTION}

Composite materials are finding increasing applications underwater, where their low specific weight and excellent corrosion resistance offer significant advantages over metallic materials. In addition to permanent contact with sea water the deep sea environment also imposes high pressures which increase with depth. It has long been recognized that hydrostatic pressure affects the behaviour of polymers [1-3]. The main effect observed is an increase in modulus and yield stress. A linear pressure dependency of shear yield stress $\tau$ has been proposed [1] of the type :

$$
\tau=\tau_{\mathrm{o}}+\mu \mathrm{p}
$$

where $\mu$ is a coefficient dependent on the polymer and $\mathrm{p}$ is the hydrostatic pressure. Modification of ductile-brittle transitions may also be observed as craze formation is suppressed at high pressure. Strain to failure may increase or decrease. Several studies have also been performed to evaluate the influence of pressure on the mechanical properties of polymer matrix composites [4-10], at pressures up to 7000 bars (700 MPa). Typical modulus variations with pressure for unidirectional composites are increases of a few percent per 100 MPa pressure increase. Tensile strength tends to decrease with increasing pressure $[4,5]$ and this has been related to increased matrix yield stress and reduced toughness. In contrast compression strength generally increases with increasing hydrostatic pressure [6-8], and the failure mechanisms have been shown to change at high pressures. In-plane shear properties also improve with increasing pressure but the fibre orientation has been shown to affect the degree of improvement [9]. A review by Hoppel et al summarized data on hydrostatic pressure effects published before 1995 [10] and concluded that more experimental and theoretical research was needed in this area. 
All the composite work described above has focussed on in-plane properties. However, failure in composite structures is frequently caused by interlaminar crack propagation (delamination) and if deep sea structures are to be optimized the influence of hydrostatic pressure on the interlaminar fracture toughness should also be quantified. Very little work has been published on out-of-plane behaviour of composites in this context. A recent paper by Rhee presented results from compressive fracture tests in a pressure vessel on unidirectional carbon/epoxy dog-bone specimens containing implanted film defects [11]. A 32\% increase in $\mathrm{G}_{\mathrm{c}}$ was measured for an increase in pressure from atmospheric to $200 \mathrm{MPa}$. At low pressures multiple delaminations were noted whereas at higher pressure a single crack propagated. These results are interesting but the change in the failure mode and the mixed mode loading make analysis in terms of Mode I and Mode II fracture toughness difficult. A special test set-up has therefore been developed at IFREMER to enable such pure loading tests to be performed. Interlaminar fracture toughness tests have been performed for many years but have only recently been standardized [12]. Mode I testing is now routinely performed using the double cantilever beam specimen (DCB) [13]. Mode II testing is more controversial and no standard test method exists yet, but the four point ENF specimen proposed by Martin and Davidson [14] appears quite attractive, combining a simple test fixture with stable crack propagation. In the present paper Mode I DCB and Mode II 4ENF tests have been performed on unidirectional carbon/epoxy specimens, in water, in a pressure vessel at pressures of 4, 300 and 900 bars. Pressure is related to the water depth by the expression:

$$
\mathrm{p}=0.101 * \mathrm{H}+0.5^{*} 10^{-6} * \mathrm{H}^{2}
$$

where $\mathrm{p}=$ pressure in bars and $\mathrm{H}=$ immersion depth in metres.

These pressures therefore correspond roughly to surface, 3000 metres and 9000 metres depth, thus covering virtually all the possible sea applications (with the exception of the deepest marine trenches in which depths descend to over 11000 metres). 


\section{MATERIALS}

The materials tested are made from Cytec IM7/977-2, an intermediate modulus carbon fibre reinforced toughened epoxy resin. Unidirectional specimens were produced from prepreg in an autoclave at Cranfield University. The specimens were de-bulked and cured under 6 bar pressure, in a single ramp $180^{\circ} \mathrm{C}$ cure. Specimens were nominally $3 \mathrm{~mm}$ thick and $20 \mathrm{~mm}$ wide. Starter cracks were obtained by placing a $10 \mu \mathrm{m}$ thick PTFE film at laminate midthickness during lay-up.

\section{TEST PROCEDURE}

Specimens were tested in a 1000 bar pressure vessel mounted on a standard 20 ton capacity electromechanical test frame. Figure 1 shows an overall view of the test set-up. The load cell is outside the pressure vessel. As the friction between the loading piston and the vessel body is significant at the low loads applied during Mode I tests, all the specimens were instrumented with strain gauges and a calibration procedure enabled load cell measurements to be checked, as discussed below.

Figure 2 shows the loading fixtures for the Mode I and Mode II tests. For the former aluminium blocks were bonded to the specimens for load introduction. For the latter the distance between the upper loading points was $60 \mathrm{~mm}$ and the distance between the lower supports was $100 \mathrm{~mm}$. A roller bearing is positioned so that the upper load points rotate about the specimen mid-thickness. The pressure vessel was closed, filled with tap water and pressurised. Strain gauge readings were allowed to stabilise before the tests were performed under displacement control at 2mm/min for Mode I, $1 \mathrm{~mm} / \mathrm{min}$ for Mode II. A digital pressure transducer was used to record pressure and these data, together with the load cell output, 
crosshead displacement and strain gage readings were recorded on a PC-based acquisition system for subsequent analysis.

The determination of $\mathrm{G}_{\mathrm{C}}$ values requires knowledge of three of the four parameters: load, displacement, crack length and modulus. For tests performed inside a pressure vessel analysis is complicated by two factors. First, the load cell of the test machine is located outside the pressure chamber. Because of the friction in the seals of the chamber and the relatively low loads expected, it was not possible to use the machine load cell directly to measure the load applied to Mode I specimens. In order to overcome this problem, all samples were instrumented with strain gauges. For Mode I tests the gauges were located on one of the DCB arms, for Mode II tests they were bonded to the lower surface of the specimen at mid-span. These strain gauges can be calibrated to act as load cells when the location of the strain gauge and specimen geometry are measured accurately (see Appendix). As strain gauges are sensitive to temperature and pressure readings were allowed to stabilise before starting to load the specimen. The second specific difficulty is that it is not easy to determine the crack lengths visually. Crack lengths were therefore back-calculated using the measured specimen compliance and assuming that the axial modulus of this material is independent of pressure over this range. This assumption is supported by published data [10] and by values measured for compliance at different pressures during fracture tests. In addition, for pressures up to 30 MPa view-glasses enabled specimens to be filmed during part of the tests, so that some calculated crack lengths and measured displacements could be checked. Figure 3 shows an example of the field of view for a Mode II test. The Mode I data analysis is performed using Equation (3) for initiation values and Equation 4 for propagation:

$$
G_{I C}=\frac{3 P \delta}{2 b a_{0}}
$$




$$
G_{I P}=\frac{1}{b}\left(\frac{3 P^{2} \delta}{2 \sqrt{E_{1} I}}\right)^{2 / 3}
$$

The derivation of these equations is given in the Appendix. The term $E_{1} I$ was measured for each half specimen using the ASTM D 790 three point bend test protocol. The validity of the load/strain relationship (equation A3) was checked by performing load/unload cycles in the linear elastic regime on an Instron 4302 test machine equipped with a $500 \mathrm{~N}$ load cell. Figure 4 shows an example of the test-calculation comparison.

In Mode II testing the load and crosshead displacement were recorded continuously, together with the strains at the centre of the specimen on the lower (tension) face. The loads are around 20 times higher in Mode II than Mode I and there is much less error in the load cell measurements due to friction, but displacement values were considered to be more reliable than force as they could be checked directly by measurements of movements made through the view-glass up to $30 \mathrm{MPa}$. Figure 5 shows an example of the machine crosshead transducer versus image analysis measurement correlation. It is clear that the values are very similar, hence the recordings of the crosshead transducer were used in subsequent analyses. In this case the strain measurements enable the exact point at which the specimen loading begins to be identified. The expression generally employed to determine $\mathrm{G}_{\text {IIC }}$ values is an experimental compliance calibration. As crack length could not be followed visually at the highest pressures (the view-glasses were only qualified for use up to 300 bars) an analytical expression was required. Such expressions have been proposed in the published literature $[14,15]$ but their full derivations are not given. An analytical expression was derived here therefore, in order to determine $\mathrm{G}_{\mathrm{IIC}}$ and $\mathrm{G}_{\mathrm{IIP}}$, Equation (5) :

$$
G_{I I C}=\frac{P^{2}}{2 b} \frac{3 L^{2}}{32 E_{1} I}
$$


The derivation of this equation is given in the Appendix.

\section{RESULTS}

\section{Mode I}

Figure 6 shows three examples of load-displacement plots from the fifteen DCB tests performed (3 at 0.4MPa, 5 at 30MPa and 7 at 90MPa). A small drop in the load is visible just after the end of linearity point showing that the crack initiation is slightly unstable, in spite of using a starter film of thickness within the ISO recommendation ( $<12$ microns). The crack initiation values are shown in Table I and it is clear that pressure has little effect on Mode I initiation. Figure 7 is a plot of the average Mode I resistance curves obtained by analysing the data using eq.3 and eq.4. For each specimen, the term EI was measured independently in three point flexure. Table I also shows mean values of the crack propagation resistance $\mathrm{G}_{\mathrm{IP}}$ taken at a crack length $\mathrm{a}=55 \mathrm{~mm}$ and the minimum and maximum values obtained. It is noticeable that the mean $\mathrm{G}_{\mathrm{IP}}$ decreases very slightly with increasing pressure, by around $10 \%$ for an increase of pressure from 4 to 900 bars.

\section{Mode II}

Twelve Mode II specimens were tested, 3 at $0.4 \mathrm{MPa}, 5$ at 30MPa and 4 at $90 \mathrm{MPa}$. Figure 8 shows an example of the load-displacement plots recorded at each pressure. Once again the crack initiation is unstable and higher $\mathrm{G}_{\text {IIC }}$ values are measured at initiation than during subsequent propagation. Values decrease towards a stable plateau. Figure 9 shows examples of the Mode II resistance curves. Table 2 presents the results obtained, for initiation and propagation. There is a significant increase in both initiation and propagation resistance 
values with increasing pressure. Values at 300 bars are 18\% higher than those at 4 bars. At 900 bars initiation values increase by a similar amount while propagation values are $25 \%$ higher than those at the lowest pressure.

\section{DISCUSSION}

The values obtained from these tests are given in Tables 1 and 2 and summarised in Figure 10. Under Mode I loading there may be a small decrease in the fracture toughness but the drop is similar to the scatter in values and cannot be considered to be significant. Under Mode II loading there is a more significant influence of pressure. One possible reason for this is the influence of pressure on the friction between the two sliding surfaces. Friction forces will be directly proportional to the applied lateral pressure on the specimen faces so the work required to overcome these would be expected to increase the measured value of $\mathrm{G}_{\text {IIC }}$. On a practical level it is apparent from these results that within experimental scatter there is no detrimental effect of hydrostatic pressure on either Mode I or Mode II interlaminar fracture toughness for this carbon/epoxy material and for the range of pressures of interest for deep sea structures. This suggests that standard tests may be used to provide conservative values in the evaluation of the damage tolerance of composites for these applications

\section{CONCLUSIONS}

The present paper describes tests performed in a specially designed test fixture which allow hydrostatic pressures up to 1000 bars to be applied during standard mechanical tests. Interlaminar fracture tests under Mode I and Mode II loadings performed at 4, 300 and 900 bars pressure have revealed little influence of pressure on Mode I fracture toughness of 
carbon/epoxy specimens. Mode II delamination resistance was increased by up to $25 \%$ for an increase in pressure from 4 to 900 bars.

These results suggest that data from standard laboratory tests can be used to provide conservative values in the damage tolerance design of these materials for deep sea applications.

\section{Acknowledgements}

This work was performed at IFREMER Brest Centre within the European METRI (Marine Environment Tests and Research Infrastructure) programme. The technical expertise of B. Leilde, N. Lanteri, J-F Rolin and A. Deuff of IFREMER in the development of the pressure vessel is gratefully acknowledged. 


\section{REFERENCES}

[1] Ward IM, Mechanical properties of solid polymers, John Wiley, $2^{\text {nd }}$ edition 1990, p357362.

[2] Pae KD, Bhateja SK, The effects of hydrostatic pressure on the mechanical behaviour of polymers, J. Macromol. Sci., Revs Macromol Chem. C13 (1), 1975, 1-75.

[3] Radcliffe SV, Effects of hydrostatic pressure on the deformation and fracture of polymers, in Deformation and Fracture of High polymers, ed Kausch HH, Hassell JA, Jaffee RI, Plenum Press 1972.

[4] Parry TV, Wronski AS, The effect of hydrostatic pressure on the tensile properties of pultruded CFRP, J. Materials Sci., 1985, 20, 2141-2147.

[5] Zinoviev PA, Tsvetkov SV, Kulish GG, van den Berg RW, van Schepdael LJMM, The behaviour of high strength unidirectional composites under tension with superposed hydrostatic pressure, Comp. Sci \& Tech., 61, 2001, 1151-1161.

[6] Wronski AS, Parry TV, Compressive failure and kinking in uniaxially aligned glass-resin composites under superposed hydrostatic pressure, J. Materials Sci., 1982, 17, 3656-3662.

[7] Weaver CW, Williams JG, Deformation of a carbon-epoxy composite under hydrostatic pressure, J. Materials Sci., 1975, 10, 1323-1353.

[8] Rhee KY, Pae KD, Effects of hydrostatic pressure on the compressive properties of laminated $0^{\circ}$ unidirectional graphite fiber/epoxy matrix thick composites, J. Composite Materials, 1995, 29, 10, 1295-1307.

[9] Shin ES, Pae KD Effects of hydrostatic pressure on in-plane shear properties of graphite/epoxy composites, J. Comp. Mats., 1992, 26, 6, 828-868. 
[10] Hoppel CPR, Bogetti TA, Gillespie JW Jr., Literature review-Effects of hydrostatic pressure on the mechanical behaviour of composite materials, J. Thermoplastic Composite Materials, 1995, 8, 375-409.

[11] Rhee KY, Hydrostatic pressure effect on the fracture toughness of unidirectional (0-deg) graphite/epoxy laminated composites, J. Comp. Mats, 34, 7, 2000, pp599-613.

[12] Moore DR, Pavan A, Williams JG, Fracture mechanics testing methods for polymers, adhesives and composites, ESIS Publication 28, 2001, Elsevier, Chapter 4.

[13] ISO 15024 (2001) Fibre-reinforced plastic composites - Determination of Mode I interlaminar fracture toughness, $\mathrm{G}_{\mathrm{IC}}$, for unidirectionally reinforced materials.

[14] Martin RH, Davidson BD, Mode II fracture toughness evaluation using a four point bend end notched flexure test, Proc $4^{\text {th }}$ Int. Conf. on Deformation and Fracture of Composites, Manchester, March 1997.

[15] Kageyama K, Kimpara I, Suzuki T, Ohsawa I, Kanai M, Tsuno H, Effects of test conditions on Mode II interlaminar fracture toughness of four-point ENF specimen, Proc ICCM12, Paris, France, 1999.

[16] Williams JG, Fracture mechanics of anisotropic materials, Chapter 1 of Application of Fracture Mechanics to composite materials, Ed Klaus Friedrich, Elsevier, 1989. 


\section{Tables}

Table 1. Mode I test results

Mode I delamination toughness, $\mathrm{J} / \mathrm{m}^{2}$

\begin{tabular}{lcccccc}
\hline & \multicolumn{3}{c}{ Initiation (5\%-Max) } & \multicolumn{3}{c}{ Propagation a= 55mm } \\
\hline Pressure (MPa) & 0.4 & 30 & 90 & 0.4 & 30 & 90 \\
\hline Average & 406 & 397 & 363 & 766 & 719 & 682 \\
Min & 387 & 261 & 296 & 724 & 597 & 604 \\
Max & 434 & 478 & 440 & 825 & 790 & 777 \\
\hline
\end{tabular}

Table 2. Mode II test results

Mode II delamination toughness, $\mathrm{J} / \mathrm{m}^{2}$

\begin{tabular}{lcccccc}
\hline & \multicolumn{3}{c}{ Initiation (5\%-Max) } & \multicolumn{3}{c}{ Propagation a= 55mm } \\
\hline Pressure (MPa) & 0.4 & 30 & 90 & 0.4 & 30 & 90 \\
\hline Average & 1548 & 1842 & 1812 & 944 & 1112 & 1186 \\
Min & 1528 & 1713 & 1773 & 884 & 995 & 1072 \\
Max & 1570 & 1929 & 1905 & 992 & 1165 & 1285 \\
\hline
\end{tabular}




\section{Figure captions}

1. Test set-up, 1000 bar pressure vessel on 20 ton capacity test frame

2. Test fixtures, a) Mode I, b) Mode II

3. Field of view for tests under pressure, a) Mode I, b) Mode II

4. Example of load-strain comparison, calculated and measured, Mode I specimen.

5. Example of crosshead transducer versus image analysis measurements of displacement for a Mode II specimen.

6. Load-displacement plots, Mode I, at different pressure levels.

7. Average Mode I fracture resistance plots at different pressure levels.

8. Load-displacement plots, Mode II, at different pressure levels.

9. Examples of Mode II fracture resistance plots at different pressure levels.

10. Summary of fracture tests, Mode I and Mode II versus applied hydrostatic pressure.

A1. 4pt ENF test configuration and notations used in the analysis.

A2. Shear Force and Bending Moment diagram section [A-C].

A3. Shear Force and Bending Moment diagram section [C-E]. 


\section{Appendix: Data Analyses}

\section{Mode I}

\section{Load determination}

Using simple beam theory and stress analysis of a beam in bending, we have:

$\sigma_{b}(x)=\frac{-M(x) h}{2 I}$

$M(x)=-P x$

Here $\sigma_{b}(x)$ is the bending stress at the surface of the beam, $M(x)$ is the bending moment at a distance $x$ from the loading point, $P$ is the applied load, $I$ is the second moment of inertia and $h$ the half thickness of the DCB beam. Consider $x$ to be the distance between the strain gauge and the loading point and $E_{1}$ is the flexural modulus of the beam, the applied load was determined from the strain gauge using the following relation:

$P=\frac{2 E_{1} I}{x h} \varepsilon$

\section{Calculation of $G_{I C}$}

The general expression of the energy release rate $G_{C}$ is given by Williams [16]:

$$
G_{C}=\frac{P^{2}}{2 b} \frac{\partial C}{\partial a}
$$

As in the previous section, $P$ is the load applied to the sample, $b$ the width of the sample, $a$ the crack length and $C$ is the compliance and is equal to $C=\delta / P$ with $\delta$ being the opening displacement.

However, using simple beam theory in the case of the double cantilever beam, the compliance of the specimen can be expressed by the following equation: 
$C=\frac{8 a^{3}}{E_{1} b h^{3}}=\frac{2 a^{3}}{3 E_{1} I}$

and $\frac{\partial C}{\partial a}=\frac{2 a^{2}}{E_{1} I}=\frac{3 C}{a}$

also $a=\left(\frac{3 E_{1} I C}{2}\right)^{1 / 3}$

Finally, $G$ can be expressed as a function of $P$ and $d$ (and for any given time) by:

$G_{I P}=\frac{P^{2}}{2 b} \frac{3 C}{a}=\frac{P^{2}}{2 b} \frac{3 \delta}{P}\left(\frac{2 P}{3 E I \delta}\right)^{1 / 3}=\frac{3^{2 / 3} P^{4 / 3} \delta^{2 / 3}}{2^{2 / 3} b(E I)^{1 / 3}}=\frac{1}{b}\left(\frac{3 P^{2} \delta}{2 \sqrt{E I}}\right)^{2 / 3}$

For the same time the crack length can be estimated using (A9):

$a=\left(\frac{3 E_{1} I \delta}{2 P}\right)^{1 / 3}$

These expressions enable $\mathrm{G}_{\mathrm{IP}}$ values versus crack length to be determined. The initiation values are calculated using the usual beam theory

$G_{I C}=\frac{3 P \delta}{2 b a_{o}}$

The correction factors $F$ and $N$ suggested in ISO15024 [13] were not used in the study as it is a comparative study. The crack length correction factor $\Delta$ cannot be determined as no visual crack length measurement was available (see [13] for more details).

\section{Mode II}

Introduction definition of the problem.

The notations used to carry out the analysis are described in Figure A1. In the following section, $y$ is the deflection of the beam, $x$ is the long axis of the beam, parallel to the crack plane. 
For clarity: $\frac{\partial y(x)}{\partial x}=y^{\prime}(x)$ and $\frac{\partial^{2} y(x)}{\partial x^{2}}=y^{\prime \prime}(x)$

The aim of the calculation is to determine the deflection $\delta$ at the centre of the loading cradle which is the mid- point between B and D.

In order to simplify the calculations, the coordinate system will be centred at the crack tip (point $\mathrm{C}$ in Fig. A1). The deflection $\delta$ of the beam due to the cross head displacement can be expressed by the following equation:

$\delta=\frac{1}{2}\left(y_{E}+y_{A}\right)-\frac{1}{2}\left(y_{D}+y_{B}\right)=\frac{1}{2}\left[\left(y_{E}-y_{D}\right)+\left(y_{A}-y_{B}\right)\right]$

The beam can now be described as two half beams which can be treated independently.

Calculation for the $1^{\text {st }}$ half beam crack end: determination of $\left(y_{A^{-}} y_{B}\right)$.

The shear force $\mathrm{T}$ and moment $\mathrm{M}$ diagrams are plotted in Figure A2.

Determination of $y_{A B 1}$ in section [C-B]:

Here we have $y_{A B 1}=\theta_{B} L=y^{\prime}(a-L)$

Moment in this section is: $M(x)=\frac{P L}{4}$

here $I=\frac{b h^{3}}{12}, b$ is the width and $h$ is the HALF thickness

Therefore after integration: 
$y^{\prime \prime}(x)=\frac{M(x)}{E I}=\frac{P L}{4 E I}$

$y^{\prime}(x)=\frac{P L}{4 E I} x$

(A14) (A15) (A16)

$\theta_{B}=y^{\prime}(a-L)=\frac{P}{4 E I}(L(a-L))$

Finally:

$y_{A B 1}=\frac{P L^{2}(a-L)}{4 E I}$

Determination of $y_{A B 2}$ : in section [B-A]

We have $M(x)=\frac{P}{4}(L-x)$

Therefore by integration of the beam equation similar to eq.A14, we obtain:

$$
y_{A B 2}=y(L)=\frac{P}{4 E I}\left(\frac{L^{3}}{3}\right)
$$

and $\left(y_{A}-y_{B}\right)=\frac{P}{4 E I}\left(\frac{L^{3}}{3}+L^{2}(a-L)\right)=\frac{P L^{2}}{16 E I}\left(4 a-\frac{8}{3} L\right)$

Calculation for the $2^{\text {nd }}$ half beam crack end: determination of $\left(y_{E-}-y_{D}\right)$.

The problem is very similar to the calculations carried out for section [AB], however, the load applied is $P / 2$.

and here: $I^{*}=\frac{b(2 h)^{3}}{12}=8 I$

Determination of $y_{D E 1}$ in section [C-D]

Here we have $y_{D E 1}=\theta_{D} L=y^{\prime}(S-a-L)$

Moment in this section is: $M(x)=\frac{P L}{2}$

Standard beam theory gives: $y^{\prime \prime}(x)=\frac{M(x)}{E I^{*}}=\frac{M(x)}{8 E I}$

Therefore after integration, using the same methodology used in eq.A14 to eq.A16 we conclude that: 


$$
y_{D E 1}=\frac{P L^{2}(S-a-L)}{16 E I}
$$

Determination of $y_{D E 2}$ in section [D-E]

We have $M(x)=\frac{P}{2}(L-x)$

Therefore after integration of the beam equation we get:

$$
y_{D E 2}=y(L)=\frac{P}{16 E I}\left(\frac{L^{3}}{3}\right)
$$

And $\left(y_{E}-y_{D}\right)=\frac{P}{16 E I}\left(\frac{L^{3}}{3}+L^{2}(S-a-L)\right)$

\section{Calculation of $\delta$ and the compliance $C$ :}

Using equations A11, A20 and A28, we obtain:

$$
\begin{aligned}
& \delta=\frac{1}{2}\left[\frac{P L^{2}}{16 E I}\left(4 a-\frac{8}{3} L+S-a-\frac{2}{3} L\right)\right] \\
& \delta=\frac{P L^{2}}{32 E I}\left(3 a-\frac{10}{3} L+S\right)
\end{aligned}
$$

The compliance is given by:

$$
C=\frac{\delta}{P}=\frac{L^{2}}{32 E I}\left(3 a-\frac{10}{3} L+S\right)
$$

$$
\text { Also } \frac{\partial C}{\partial a}=\frac{3 L^{2}}{32 E I}
$$

Finally, the Mode II delamination toughness is defined by:

$$
G_{I I C}=\frac{P^{2}}{2 b} \frac{3 L^{2}}{32 E I}
$$

If the flexural modulus is known, the crack length can be calculated using eq (A33):

$$
a_{c a l}=\frac{1}{3}\left[\frac{32 E I C}{L^{2}}+\frac{10}{3} L-S\right]=\frac{1}{3}\left[\frac{32 E I \delta}{P L^{2}}+\frac{10}{3} L-S\right]
$$




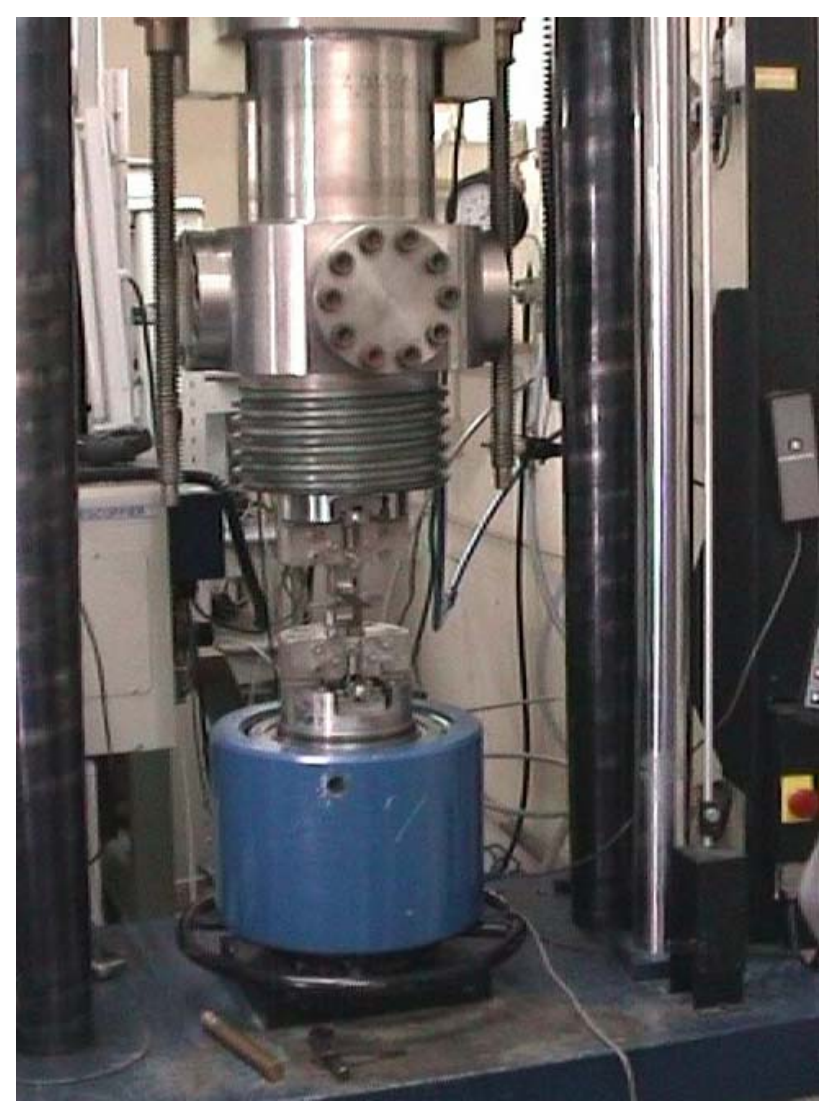

1. Test set-up, 1000 bar pressure vessel on 20 ton capacity test frame 

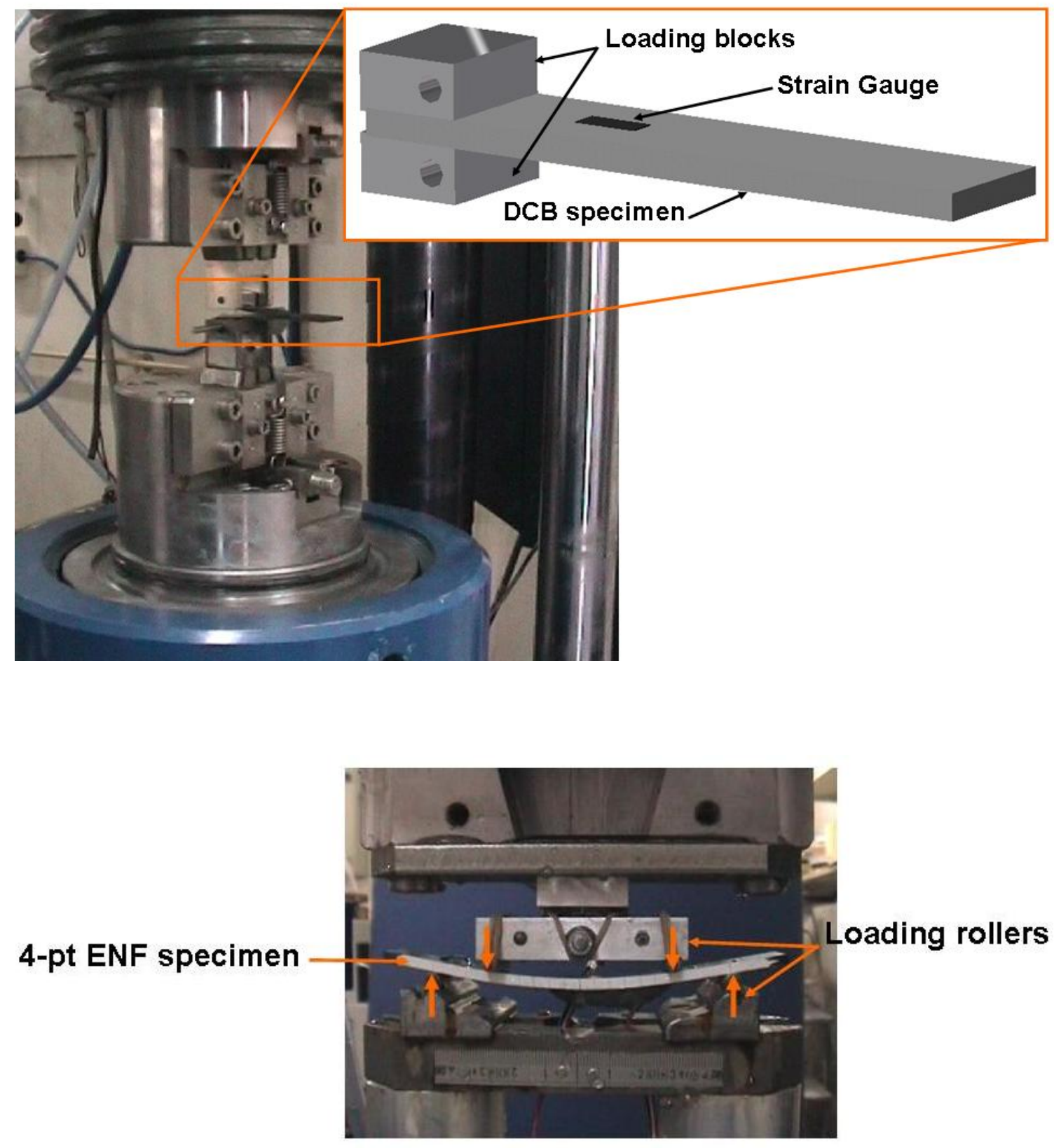

2. Test fixtures, a) mode I, b) mode II 


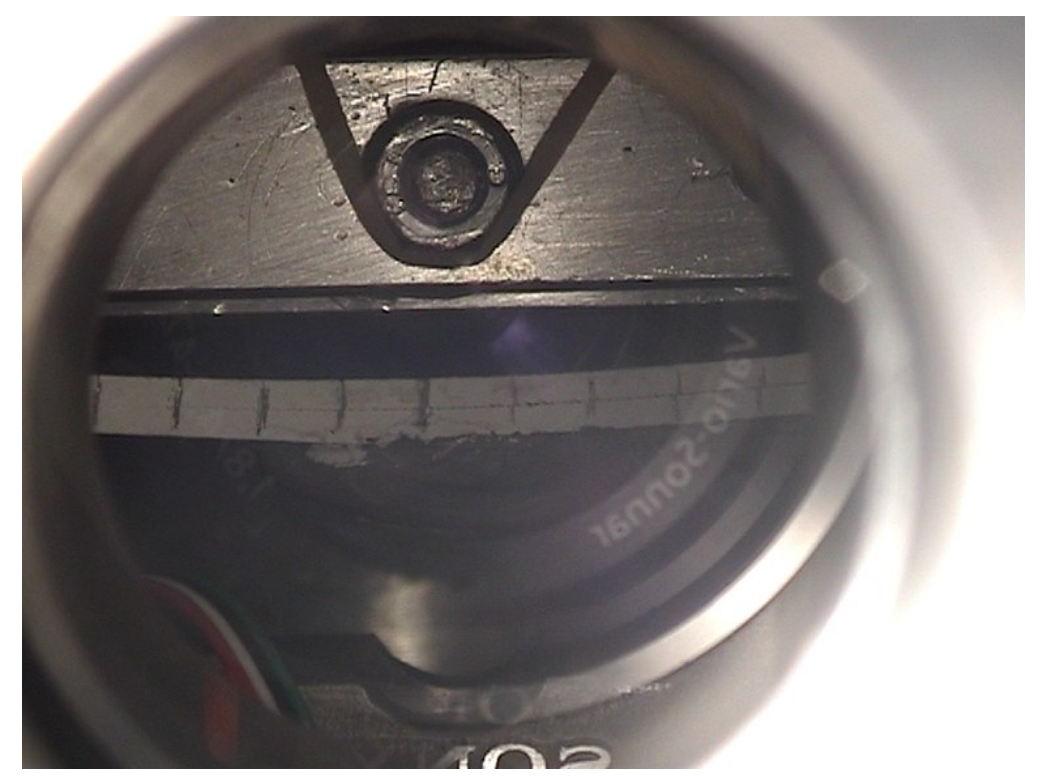

3. Example of field of view through view-glass for mode II test under pressure.

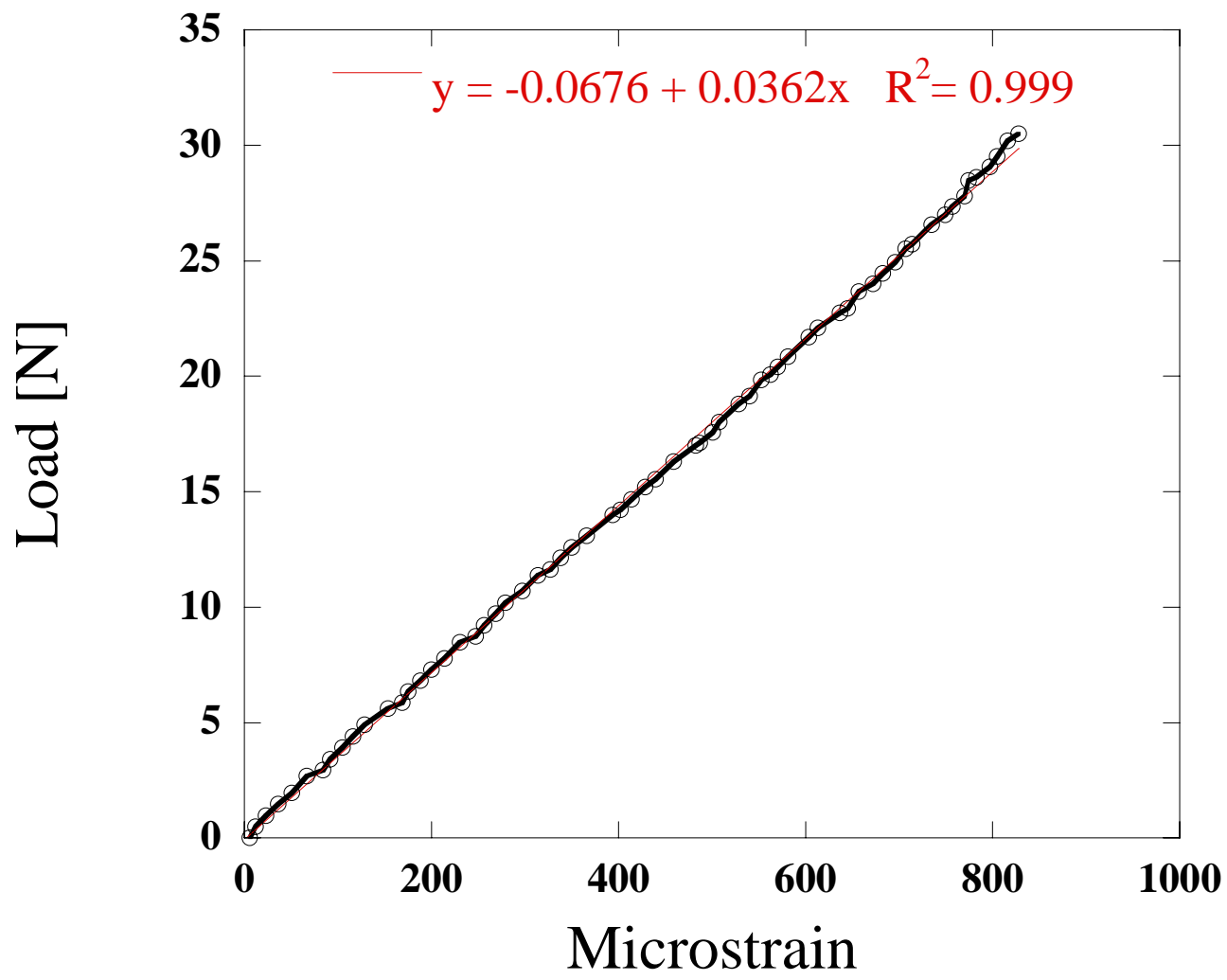

4. Example of load-strain comparison, calculated and measured, mode I specimen. 


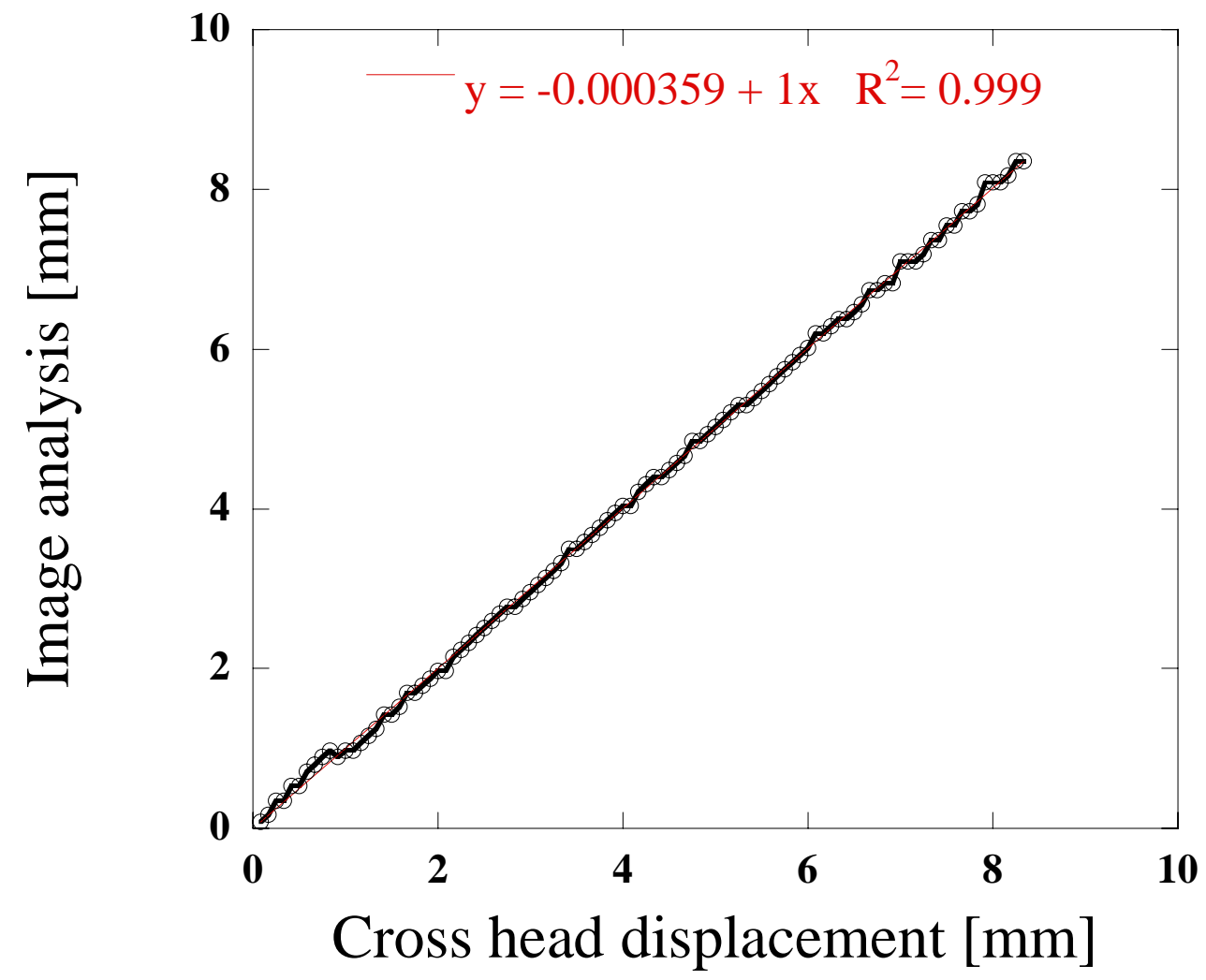

5. Example of cross-head transducer versus image analysis measurements of displacement through view-glass, Mode II specimen. 


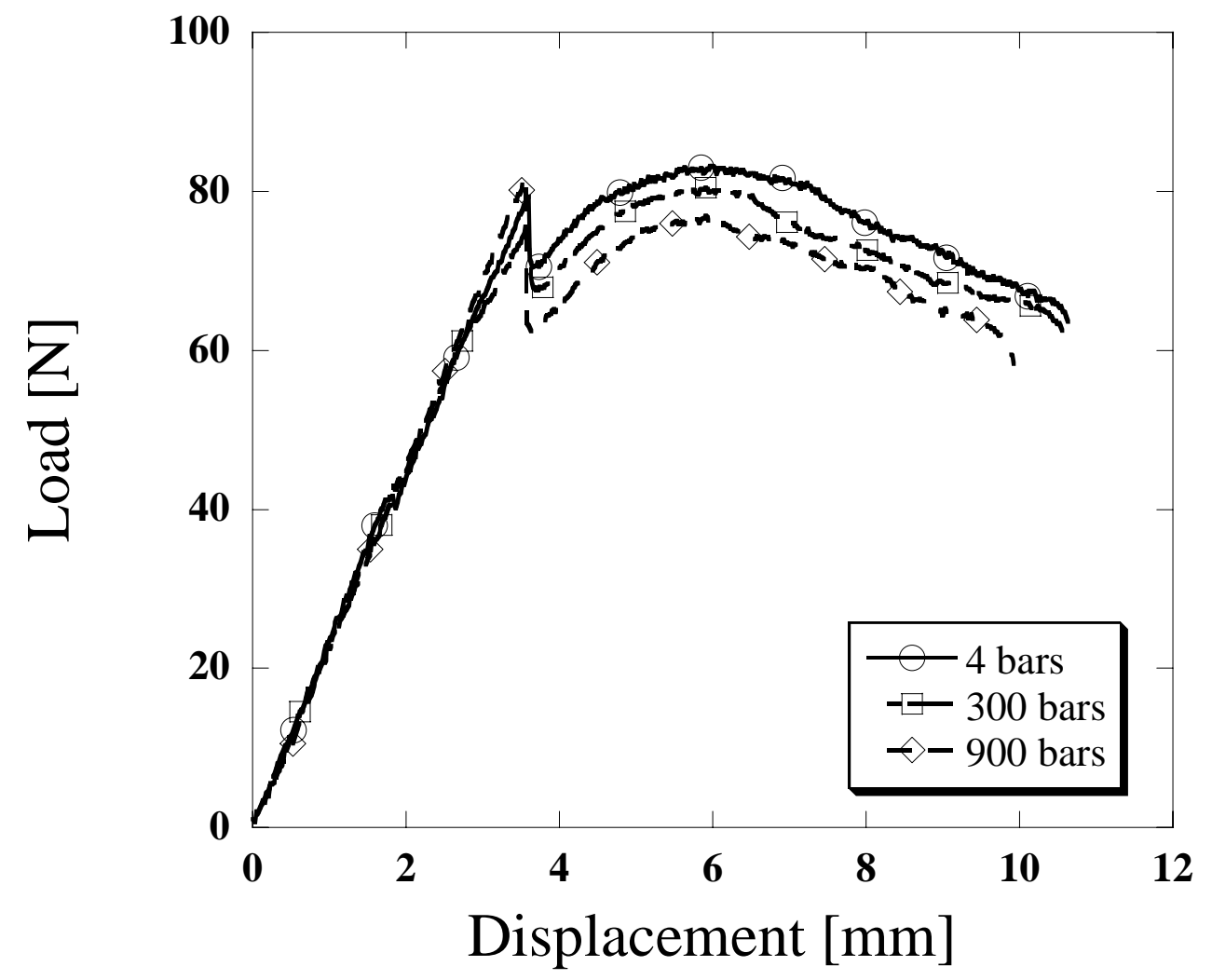

6. Load-displacement plots, mode I, at different pressure levels 


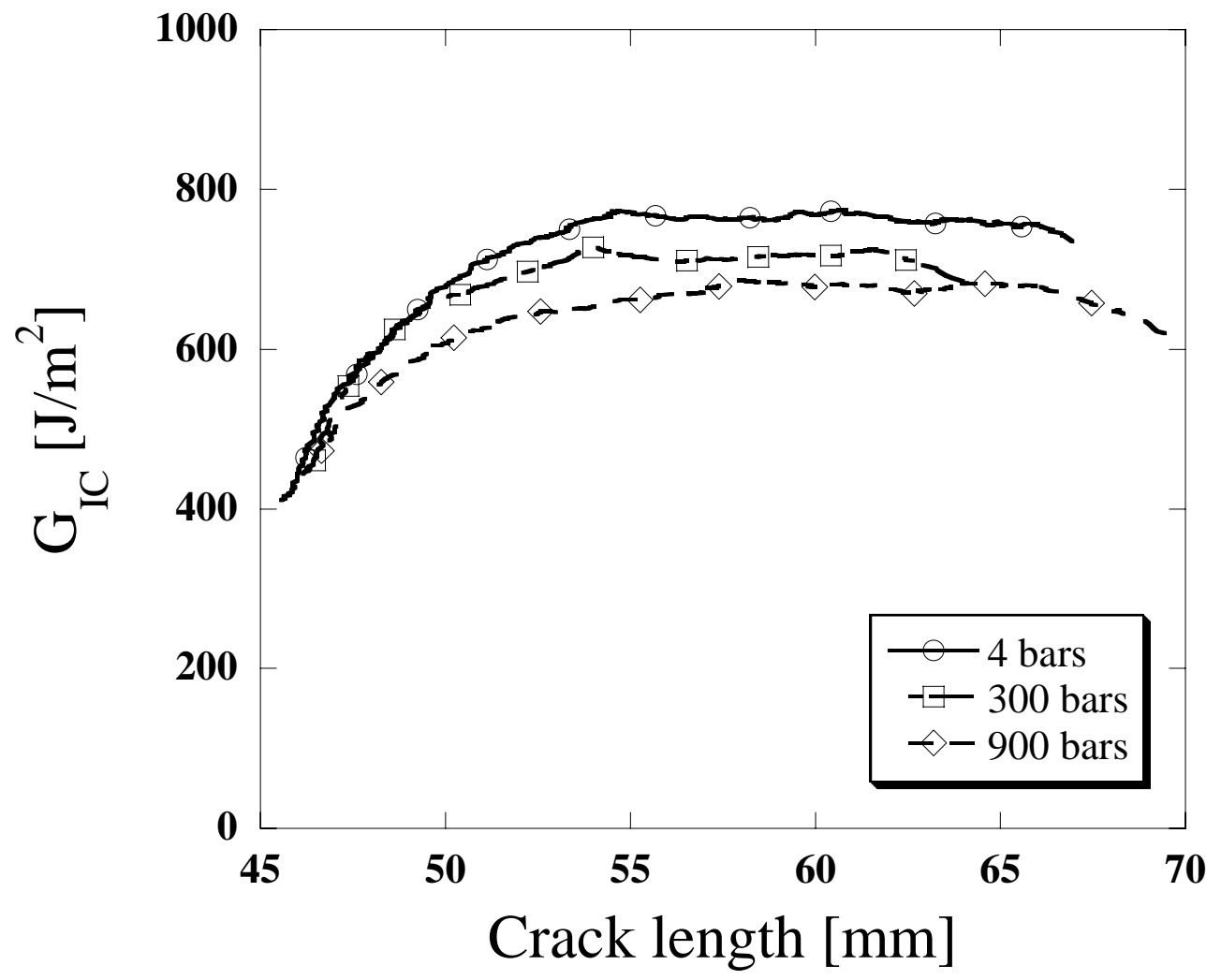

7. Average Mode I fracture resistance plots at different pressure levels 


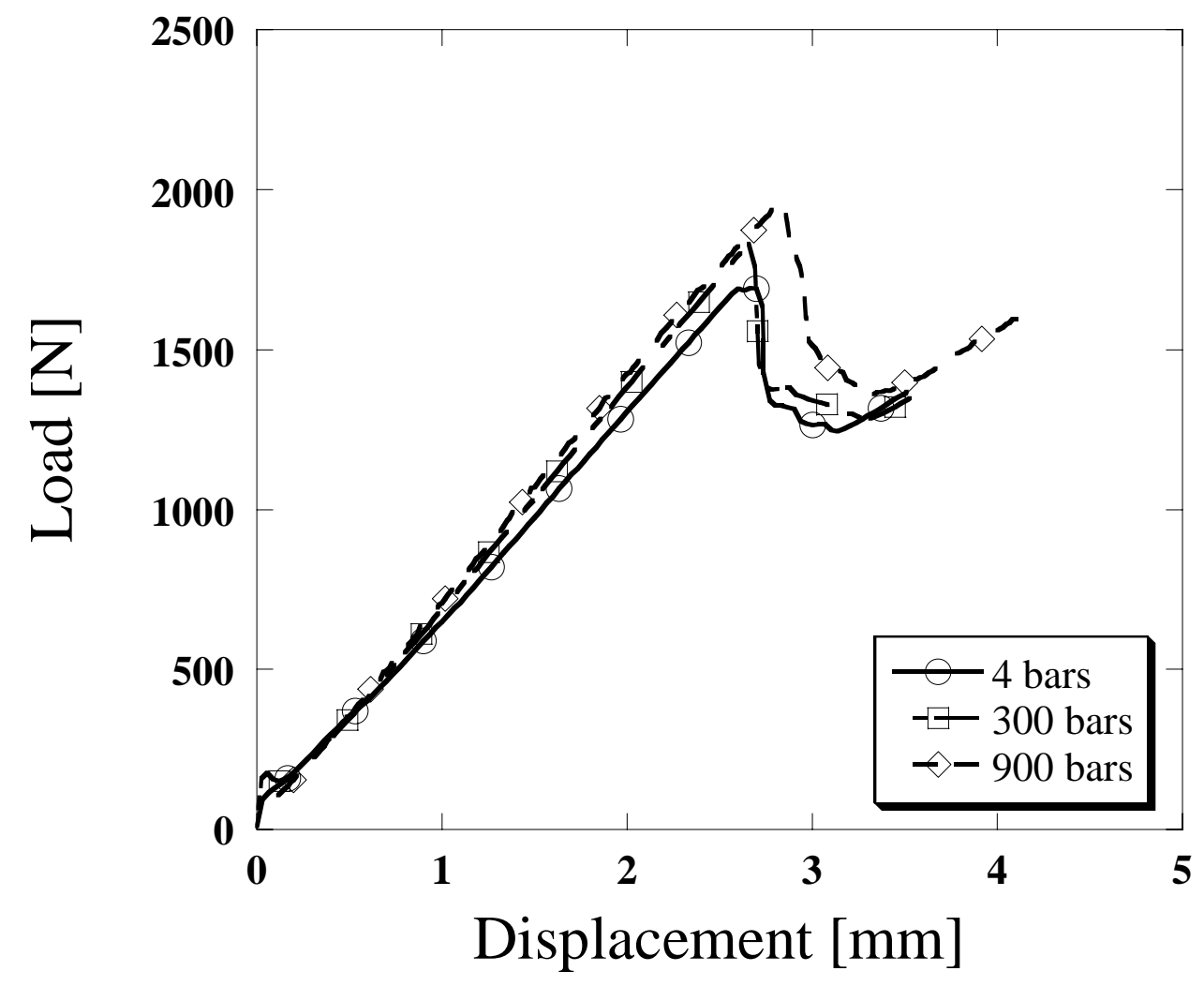

8. Examples of load-displacement plots, mode II, at different pressure levels 


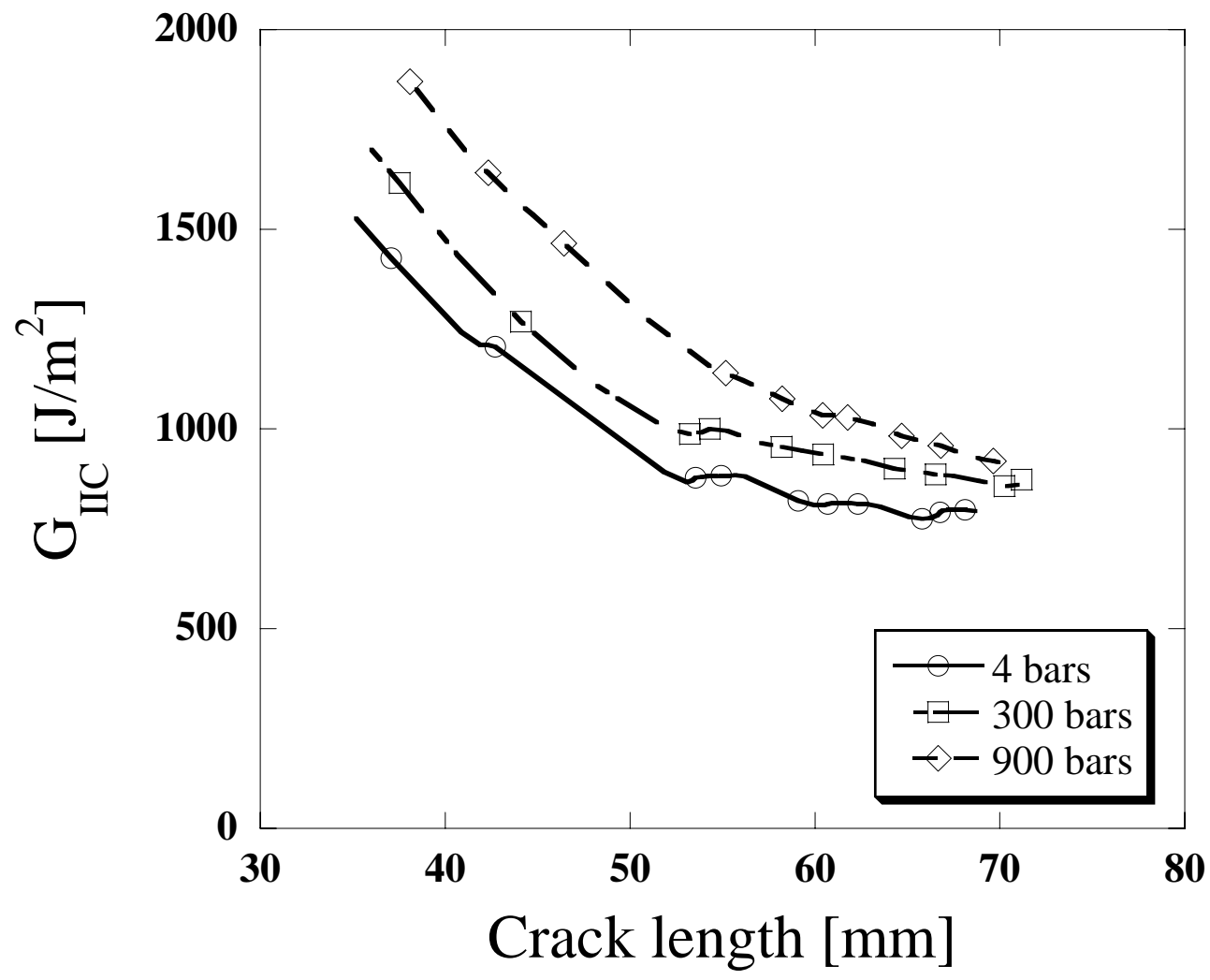

9. Examples of Mode II fracture resistance plots, at different pressure levels 


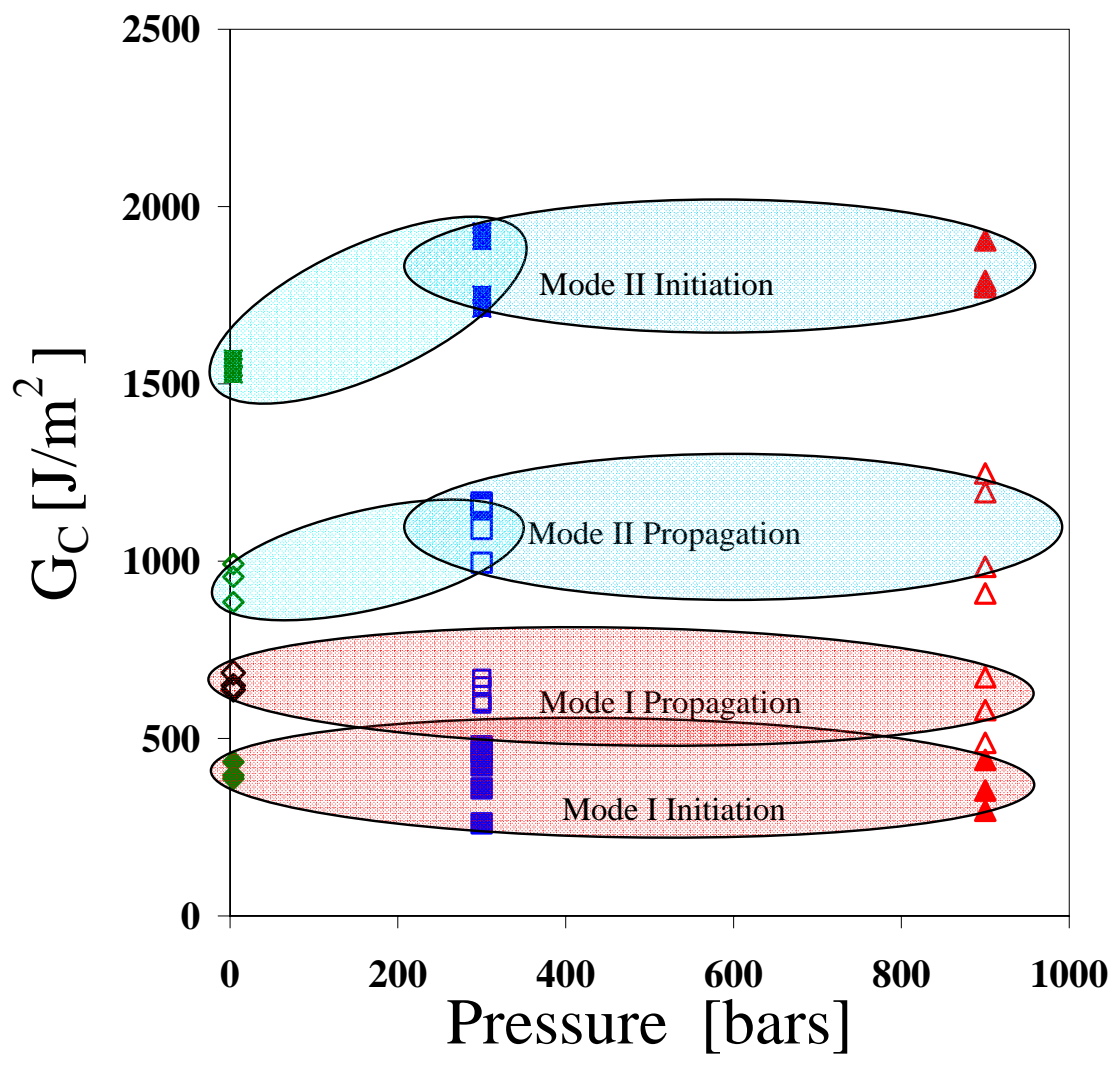

10. Summary of fracture tests, mode I and mode II versus applied hydrostatic pressure.

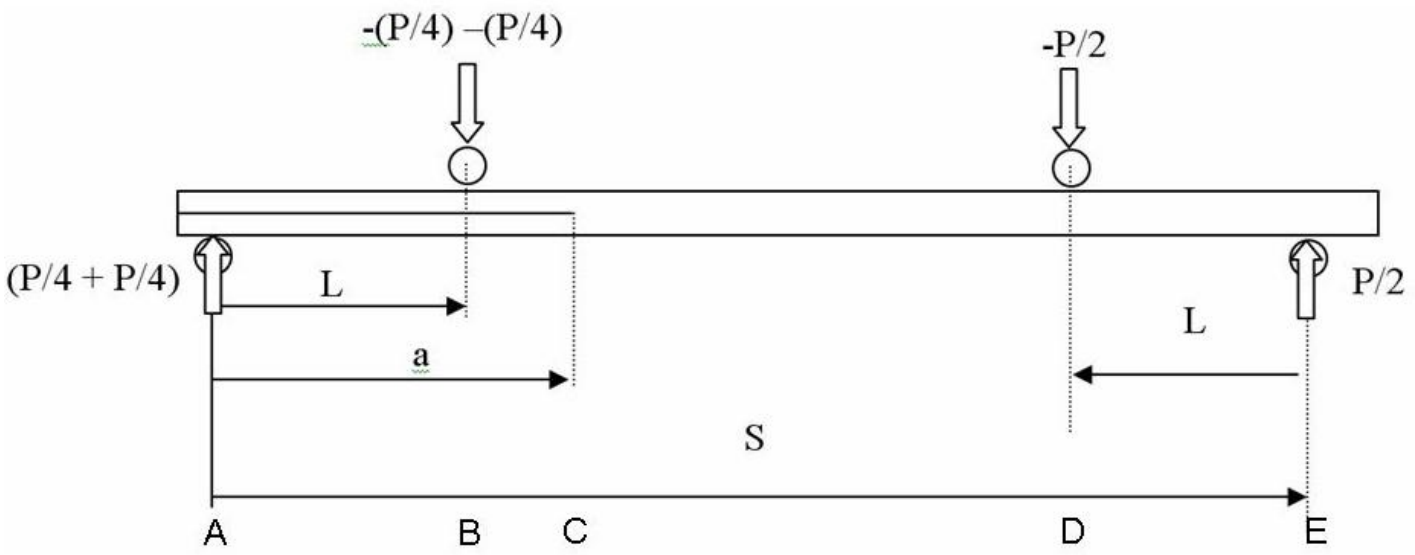

A1. 4 point ENF test configuration and notations used in the analysis 

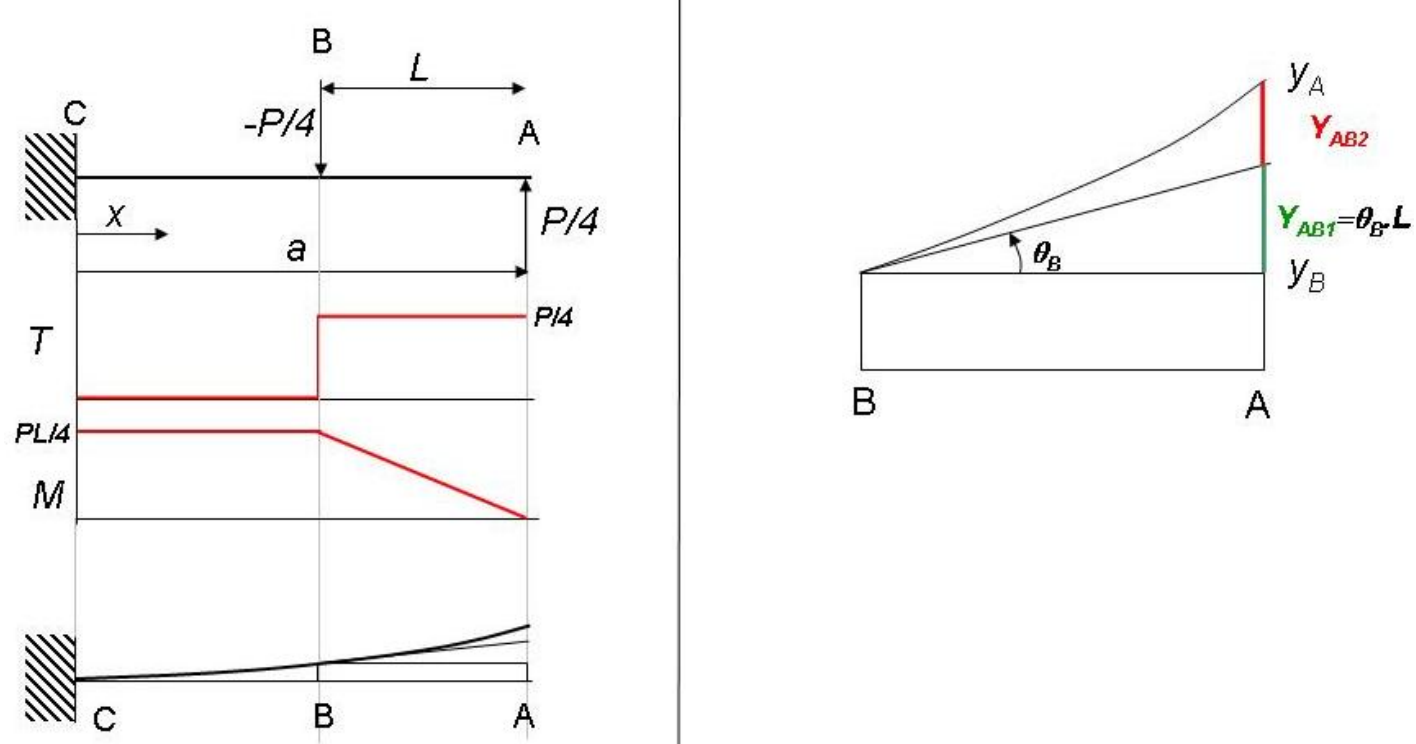

A2. Shear Force and Bending Moment diagram section [A-C]

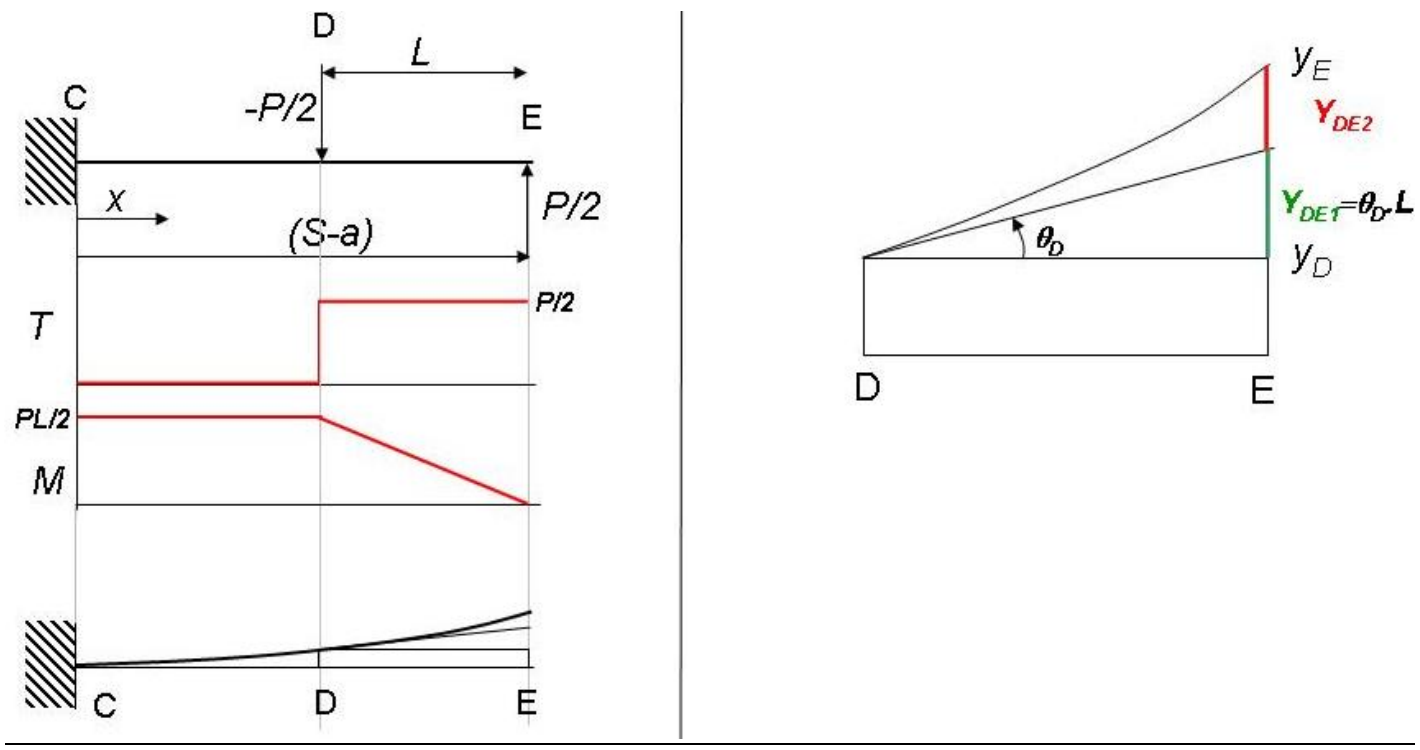

A3. Shear Force and Bending Moment diagram section [C-E] 